\title{
REPORT OF THE STANDING COMMITTEE ON SILVICULTURE
}

\author{
BY DES CROSSLEY ${ }^{1}$
}

When Lowell Besley, as President of the Canadian Institute of Forestry, asked me to chair the Standing Committee on Silviculture he expressed concern over the timidity and lack of conviction among Canada's professional foresters. "Too many of our foresters become discouraged with the limited prospects of putting their interests and knowledge to practice and seem to give up. They find senior management unresponsive to suggestions for intensive forestry-l would like to see your committee stimulate new approaches and new thinking". This was an exciting challenge.

To obtain a Committee $I$ requested permission to forego the usual method of accepting men named by the various Sections across Canada. Instead, the privilege was granted to choose them myself and $I$ have not had cause to regret such a procedure. The assignment and inter-committee correspondence have been exciting and stimulating. My concern is that $I$ may be unable to do justice to the wealth of ideas and varied reactions that were received as the many facets of the problem of getting silviculture into practice were presented and deliberated.

At the outset it is significant to relate that no unanimity of opinion appeared among committee members with regard to senior management's avowed unresponsiveness to suggestions for intensive forestry. However, many examples of lack of concern did flow in from across the country. Instances were related of clear cutting huge areas with unconcern, and waiting for long periods for natural regeneration; overcutting of accessible areas close to the point of consumption; deceiving the public with misleading news releases, extravagant claims and half truths; prominent agencies not measuring up to their responsibilities in public education; senior management taking shelter behind the long range nature of the forest enterprise as an excuse for disregarding the need for future timber supplies. Nevertheless, through this threnody of despair, as widespread as it undoubtedly is, shines the fact that some companies, some organizations are making progress in this field. If some can do it, why cannot it be done by all? Your Committee determined to explore the problem as thoroughly as time permitted.

\footnotetext{
${ }^{1}$ Chief Forester, North Western Pulp and Power, Hinton, Alberta - Chairman; Members: Ken Armson, Toronto, Ontario; George Brown, Ottawa, Ontario; Pat Duffy, Calgary, Alberta; Leif Holt, Liverpool, Nova Scotia; Jack Jarvis, Winnipeg, Manitoba; Alan Moss, Kelowna, B.C.; Dave Story, Port Arthur, Ontario; Jack Walters, Haney, B.C., and Gordon Weetman, Montreal, Quebec.
} 
In reviewing the work done by previous Standing Committees on Silviculture our interest was aroused by the report of the 1956 Committee under the Chairmanship of George Allen. His group concluded its term of office reporting that silviculture by incentive was the most practical lever to induce the forest owner or operator to practice silviculture on his holdings. He must be made aware of the advantages to be gained. Allen's Committee concluded that "the forester's greatest responsibility lies in seeking out, investigating carefully and reporting clearly on practices that offer advantages and benefits to his principal".

Impressed by this common sense approach our Committee could do no better than borrow it. We set out to investigate and report on incentive silviculture. The approach adopted was to examine current silvicultural practices with a jaundiced eye, challenging everything doubtful, searching out and recognizing failures in current practices. With such an approach in mind we chose the appropriate title "The Devil's Advocate" for our periodic progress bulletin. George Bernard Shaw once said that he liked fighting successful people "attacking them, rousing them, trying their metal, kicking down sand castles so as to make them build stone ones . . . It develops one's muscles. Besides, one learns from it". Our Committee intended to learn and to profit by kicking down sand castles.

Hugh Hodgins, a past President of the Canadian Institute of Forestry, stated at the 52nd Western Forestry Conference "if we do not find means to remain competitive product-wise and cost-wise we might as well forget about intensive forestry. We must generate in some manner dollars that can be diverted to intensive forestry". Our Committee therefore set about to discover methods of generating dollars that could be applied to intensification of current silvicultural programmes in the long-range interest of our principles.

Faced with the digressions that are an inevitable but interesting part of the deliberations of a wide-spread and free-ranging committee, and in touch only by the written word, it is my task as Chairman to attempt to present the Committee's findings as logically and as comprehensively as possible. Initially I will set forth six criteria, the recognition of which we felt was fundamental to the task.

1. It was recognized and deplored that it appears currently popular to make the cost of silvicultural practice the scape-goat of high wood production costs. The Committee agreed that a worthwhile silvicultural programme can be conducted at an approximate cost of $2 \%$ of the cost of laying down a cord of wood in the mill yard. Obviously the elimination of such costs would have little significance on improving the competitive position of wood products in world markets.

2. Significant monetary savings can best be made in the fields of wood handling and transportation, and reduction in woodyard inventories. Because of the big bite that transportation takes out of wood procurement costs the idea of resuming the nomadic search for additional wood supplies in unexplored and undeveloped areas should seldom be considered. The intensification of silviculture can increase yield on present holdings at relatively little cost. In this connection an article in the March, 1962 issue of Forest Science caught the Committee's attention. "Resource Inputs and Output Growth; Comparisons between Agriculture and Forestry" by Ruttan and Callahan. This timely study critically 
examines the widely held view that natural resources are scarce and becoming more so. By assuming comparable technological changes in forestry in the future (timber production, harvesting and utilization) as we are presently witnessing in agriculture, we can expect to move ahead at a sufficiently rapid rate to continue to overcome the effects of our increased demand for forest products. They conclude with the statement, "Instead of talking about the increasing acreage required to meet output requirements, discussion may have to shift to the number of timber acres that can be shifted to recreational or other uses in order to obtain favorable timber prices". An increase in our output potential will result from intensification of silviculture. The degree to which it is practised will dictate which forest industrialists remain in business.

3. Intensified silviculture and intensified forestry are one and the same thing. Ergo, dollar savings that can be effected in any aspect of the forest management field can legitimately be applied to intensification of silviculture.

4. In the specific field of regeneration silviculture the Committee agreed that the timber harvest must carry the burden of the cost of establishing the new crop. Dean Wright's statement made in his paper "Some Approaches to Regeneration from the Logging Standpoint" provided support for this stand when he stated that the "harvest of the crop and the regeneration of the new are complementary problems", and "if the strong arm of government policy supported by an enlightened industry requires that the forest assets be maintained, the current cost of the programme should be charged off as a current expense".

5. Because of the inevitable growth of world populations and the rate of economic development the demand for forest products will continue to grow in order to keep pace with expanding needs. Dr. Egon Glesinger, former Director of F.A.O.'s Forestry and Forest Products Division, has estimated that world supply of forest products will have to be doubled every 10 years.

6. As in agriculture the increase in forest output potential will flow from a similar adoption of the mechanistic approach. Your committee spent considerable time discussing this thesis. Both by training and inclination most silviculturists feel that the biological forces, and how they interact, make by far the most interesting part of forestry. It is obvious that there is general reluctance to accept the passing of the Golden Age of Forestry as practised in Europe, where the goal was to biologically manage every acre to maximize wood quantity and quality growth, regardless of cost. Such reluctance may be one of the main reasons why the contemporary silviculturist and the industrial forest manager often find themselves unable to communicate. With large-scale husbandry as practised by agriculture as an example of the benefits to be gained from modern technology it is apparent that maximum crop yields and maximum financial returns do not necessarily go hand in hand. For example, in the use of soil amendments the agriculturist largely ignores varying requirements across his fields and applies an average fertilizer treatment in order that he can reap the greater returns that result from mechanization and unhampered movement. In the final analysis, of course, both the forest manager and the agriculturist must weigh all the information at their disposal. The acceptable approach, even in this mechanical age, cannot entirely ignore biological data. On the contrary, with treatment diagnosis dependant upon 
cost projections and investment alternatives, gearing the silvics of the species to the mechanical approach will doubtless take all the skill we can muster. In all fairness I cannot state that the Committee members unanimously agreed on the relegation of the biological approach to an ancillary position, but, on balance, it was the conclusion of the majority.

In presenting the idea of incentive silviculture some of the advantages and benefits to be gained through forest husbandry may have escaped the attention of our principals. As the opportunity arises it might be well for each of us to emphasize them. Four of the more obvious are presented here:

(1) Wild land from which timber is originally harvested can, by intelligent husbandry, be made to yield 2, 3 or even 4 times as much wood in subsequent harvests.

(2) Repeated cuts from the same area will, in the long run, produce cheaper wood and perhaps stabilize the labor force.

(3) The forest industrialist who can draw on highly productive acres close to the point of consumption is going to be around much longer than those competitors who are nomadically searching for wood supplies.

(4) The current trend is toward long range management. Careless husbandry of renewable resources will not long be countenanced. How much better it is to have one's house in order than to gain the sobriquet of despoiler, and ultimately be denied the right to manage!

If you can demonstrate to your principles that your professional knowledge can extricate them from awkward positions you may generate sympathy toward a progressive programme. For example, some companies presently find themselves unable to acquire additional raw timber supplies, at least without accepting seemingly prohibitive transportation costs. If it is important to increase product output, additional timber supplies may be immediately available from present limits through an intelligent appraisal of those things that are currently minimizing the allowable cut. For example, if some of the money that would otherwise be spent on increased wood transportation costs were spent on increasing the efficiency of the protection system a reduction in allowable annual burn could likely be effected. Cutting the allowable burn in half could automatically increase the annual allowable cut by many thousands of cords. In this connection, for those companies not presently utilizing firekilled material the allowable cut can be increased immediately if provision can be made for its consumption. The pulp manufacturer might be forced to introduce rossing in order to eliminate any possibility of charcoal entering the system, but such an operation could be far cheaper than incurring increased transportation costs by going farther afield for additional green wood supplies. A second example-careful collection and compilation of growth data has, in some instances, resulted in the knowledge that rotation ages have heretofore been set too high. Legitimate reductions in this area can result in immediate increases in allowable cut. An additional example-reduction in the regeneration phase of stand management can reduce the selected rotation age with a consequent increase in allowable cut. Finally, perhaps it has not been fully appreciated that it is permissible to temporarily overcut one's limits, provided a programme of sustained yield management has been embarked upon. Most of us find ourselves managing limits that support a plethora of overmature 
stands and more rapid harvesting would put stagnant acres back in production. Exceeding the allowable cut during the early years in the rotation could be justified provided that plans are made to find compensatory timber volumes at a later date. This could be done by the eventual introduction of a thinning regime (when such a programme becomes economically feasible) or one could anticipate eventual compensatory improvements in the reduction in allowable burn.

At this point I would like to remind you of Hugh Hodgin's exhortation that dollars must be found if we wish to practice intensive forestry. The next portion of this report will deal with examples of how dollars can be found, using the Devil's Advocate approach of tearing down in order to build up, or George Bernard Shaw's admonition to kick down sand castles in order to build stone ones.

One of the most striking examples of unearthing money for subsequent reallocation was brought to light through the efforts of one of our Committee members who is also an industrial forester in British Columbia. Accepting his role as Devil's Advocate he cast a jaundiced eye over the Government Regulation that requires that slash be disposed of on his Tree Farm Licence. The lopping of slash was costing him approximately 80 cents per cunit of wood harvested, or $\$ 24,000$ per year. Was such an expenditure justified? In order to find out, two logged-over areas were left unlopped and the effect of snow packs watched. After two years the areas presented a reasonably comparable appearance with lopped areas. These results prompted queries with the B.C. Forest Service as to the need for slash disposal by lopping in the area in question. The upshot was that government regulation on the Tree Farm Licence was modified and $\$ 24,000$ a year are released to silvicultural operations yielding much more positive results.

A somewhat different approach to the expensive business of slash disposal was presented to the Committee by our industrial forester in Alberta. The Alberta Forest Service remains unconvinced that unlopped slash constitutes an acceptable fire hazard. On the other hand it agreed to the practice of scarification as an acceptable substitution for lopping. Using a figure of 25 cents a cord for lopping, its elimination results in an average saving of $\$ 7.50$ per acre. This amount is allocated to scarification and covers half the cost. Scarification reduces the fire hazard on cut-over areas acceptably and a receptive seed bed is prepared for the new crop.

Regeneration silviculture was given the Devil's Advocate approach. It was agreed that current techniques are unsatisfactory, in that each embraces one or more features unacceptable to high yield silviculture. These are: lack of species control, density control, quality control, encompassing too short an operational season, or at too great a cost. It has been demonstrated that adequate natural regeneration can often be obtained through scarification at a reasonable cost. However, quality control is impossible and density control is limited. Conventional planting methods, while they permit quality and density control, are confined by their short operational seasons and excessive costs and usually include an undesirable growth check. Broadcast seeding loses control of quality and density and its success will vary with the fluctuations in the rodent cycle. Spot seeding can regain control over 
quality and density, at the expense of accepting clumpy regeneration. Its success is also dependent on rodent populations. The current popularity for the idea of obtaining regeneration by controlled burning may prove to be a cheap and interesting tool but its success as a slash disposal and regeneration technique will be clouded and its application limited because of lack of quality and quantity control, and also because of the dangers inherent in such a practice.

As an alternative to the accepted methods of regeneration silviculture your Committee is intrigued with the possibilities of tube or bullet planting, and is watching with a great deal of interest the experimental work that is in progress. If successful, here is a method of stand replacement that promises to embrace all the criteria with which the Committee circumscribed itself. Species and density control, quality control through the use of elite seed, operational freedom through use of the entire frost-free period, at a reasonable cost that should not exceed $\$ 10.00$ per acre.

The Committee agreed that forest site classification is fundamental to any silvicultural programme, and the problem of settling on a feasible approach at a reasonable cost was undertaken. Canada stands at the forefront in the world today in the approaches to and the development of forest site classification systems. The Committee therefore had a wealth of ideas upon which to draw.

It was inevitable I suppose that some Devil's Advocate should raise the question of what use is a forest site classification, at least in the present stage of rudimentary management? After considerable discussion the Committee concurred on the following seven justifications:

(1) An intelligent management plan would be impossible without a knowledge of potential as opposed to current productivity.

(2) Comparably productive management units that will stand up in the second and subsequent rotations depend upon a forecast of productivity. Delineation of such units cannot wait without accepting administrative confusion and loss of a balanced allowable cut.

(3) Delineation of areas suited to natural regeneration of to artificial amelioration of an otherwise unreceptive seedbed.

(4) Delineation of those areas where immediate weed invasion would be liable to inhibit the establishment of regeneration.

(5) Delineation of terrain susceptible to soil erosion following logging or burning.

(6) Delineation of coarse materials deposits for road building and surfacing.

(7) Delineation of areas of greatest potential productivity where maximum returns can be expected for every silvicultural dollar spent.

Many more reasons can be catalogued to support the need for a workable system of forest site classification and the Committee felt justified in proceeding in its attempt to find a system that it could recommend. It agreed upon three specifications that were to be met before the classification system could receive the seal of approval.

(1) It must initially embrace five (5) or six (6) productivity classes, and be readily adaptable to further refinement. 
(2) While arboreal vegetation could be used as a guide, the classification into productivity classes must not be dependent upon it.

(3) It must be capable of rapid completion at a reasonable cost.

At this point it should be emphasized that the Committee saw no reason that every forester need be able to classify site. All that a forest manager requires is a map delineating his sites, plus the ability to understand the significance of what he is looking at.

In line with its avowed intention of saving dollars to spend on silviculture it must be equally apparent that the Committee could not justify recommending any site classification technique that management is unable to afford. Consequently a per acre cost not to exceed ten (10) cents was agreed upon.

Many systems of forest site classification were studied and discussed. The one that gained the support of the majority of the Committee and adequately fulfills the three requirements that were considered essential to gain its approval was the physiographic approach. While many systems have much to recommend them it appeared obvious that rapid completion at a reasonable cost dictated the use of airphotos and the extraction of information therefrom by stereoscopic study and interpretation. Any system that required more than a bare minimum of ground study or checking could not possibly qualify.

Surficial materials are readily recognized on aerial photographs by one trained in geomorphology. Their delineation provides the necessary framework or skeleton upon which to build forest behavior refinements. Such refinements are based on the assumption that productivity differences can be interpreted from the factors of soil moisture, fertility, temperature and exposure to drying, which, in turn, are interpreted from a recognition of the specific parent soil or geological material that contributes to a specific moisture regime and drainage pattern. Slope and aspect are readily recognized and play their part in the delineation of productivity classes. While existing forest stands can be a very definite aid to the interpreter and are of particular importance in the early stages of his training, their presence is by no means obligatory.

The Committee is fully aware of the fact that the quality of interpretation will depend upon the experience and ability of the photo interpreter. As previously mentioned it adopted the premise that the classification technique per se need not be fully understood by the average forester, and that site interpretation is a job for the specialist who will provide the forest manager with the maps and information necessary for intelligent appraisal of his task.

At this point it should not be amiss to suggest that, in partial return for your tax dollar, you have every right to approach the Geological Survey of Canada for assistance in the construction of surficial geology maps that are the basis for the physiographic classification of site.

Unfortunately time did not permit your Committee to thoroughly investigate additional methods of saving dollars to be applied to silviculture, although many more were suggested. However, it was never its intention to attempt to catalogue; rather, it hoped to develop the logic of incentive silviculture by illustrating with examples.

At this point it is pertinent to relate an interesting and curious little legend concerning the discovery of Brazil by the Spanish explorer, Vincente Pinzon. 
The dawn of the 16th century found his little fleet of four caravels off the coast of South America, becalmed in the tropical doldrums. Throats parched, lungs scorched, the men had long since drained their buckets dry. Now, tormented by thirst, they could only sink to the decks and pray for deliverance. Perhaps it was only a delirious fancy that made one of the sailors arise and declare he had heard a voice from afar, saying "Drop your buckets where you are."

Nevertheless he lowered his bucket into the sea, withdrew it, and before the astonished gaze of his comrades, drank his fill. They too dipped their buckets and were overjoyed to find the contents fresh and cool. Unknowingly, they had sailed upon the broad mouth of the Amazon, and their buckets contained water flowing from the inland mountains of a new empire.

In the search for silvicultural dollars we would strongly recommend your "dropping your buckets where you are". There must be some aspects of your operation that lend themselves to the reduction in cost, providing you have the desire to seek them out and the wit to recognize them. Perhaps they are peculiar to your terrain, the species with which you are dealing, the climate, your organizational set-up, the peculiar abilities and interests of certain members of your staff. The possibilities are exciting and limitless. Look into your inventory methods; perhaps they are applicable to the use of electronic computors. Are you making full use of the wealth of information contained in aerial photographs; are you taking advantage of the tremendous savings that result from the integration of operations; are you wasting money in the repeated handling of wood, and in maintaining huge woodyard inventories; are you availing yourselves of the many technological developments that are literally overwhelming us; are you aware of the advantages of government assistance wherever it is available? You may be literally standing in cool, clear water.

During Committee deliberations the subject of forest research kept popping up. How could the forest manager hope to sell silviculture without the necessary basic research, with subsequent field trials yielding firm and attractive costs. It was agreed that basic research and pilot scale trials were the duty of the research organizations, but that large scale field trials should be the responsibility of those intending to use the proposed techniques. The reluctance to assume this obligation is largely responsible for the fact that many promising techniques die aborning.

The march toward mechanistic silviculture is one that must be recognized by research planners. Forest research must undergo a change in emphasis if it is to spearhead the advance toward sustained yield forest management. There is no point in wasting time on practices that conflict with modern technology. For example, no purpose would be served in the study of two-cut shelterwoods when such a harvesting technique is obviously incompatible with the mechanistic approach. Instead the new technologies must be exploited to the full. For instance, if the proposed technique of bullet or tube planting continues to justify its early promise a crash research programme should be initiated to get the most out of it. It would be important to know as much as possible about the culture of tree seedlings in individual containers, how to 
produce the sturdiest possible seedling in the shortest possible time at the cheapest possible price. This regeneration method may completely revolutionize current forest nursery practices and render obsolete many of the techniques so laboriously learned in the past. Sight should not be lost of the possibility of an exciting new technique failing due to the lack of imaginative and timely research adequate to overcome initial problems.

Before leaving this important subject of forest research I would dwell a moment on a problem that must face every forest manager. This is the almost overwhelming avalanche of trade and scientific journals and reports that cross his desk. Since he cannot possibly read it all what a pity it would be if he were not induced to spend some time on a matter of importance to him and to the success of his operations. Time after time you must have been attracted to a paper, either from the subject matter revealed by the title, or the reputation of its author, only to be discouraged from aggressively perusing its contents after bogging down in a welter of unfamiliar jargon. Too many research foresters appear to be talking to their scientific colleagues rather than to those foresters who are in a position to put their findings into practice. The author must overcome any desire to parade his erudition else he will lose the main audience he should be attempting to capture.

In conclusion your Standing Committee believes that under one authority or another the climate is right and the stage is being set for the sustaining of yield. The public temperament is such that it will not long continue to tolerate lack of husbandry of its renewable resources. It therefore follows that any forest organization that cannot or will not accept the challenge will lose its right to manage its own resources, and will become circumscribed with government regulations and decisions and the frustrating delays and maddening mistakes that are an inevitable result of absentee administration. It is therefore our recommendation that every forest manager who complains that he cannot obtain adequate funds to undertake a sustained yield programme give serious thought to the incentive approach. Determination, imagination and "the dropping of buckets" are the ingredients for success. 